\title{
23 Conventional Defence for Europe
}

Conclusions of the organisers of the international workshop 'Emerging Technologies and Military Doctrine', Free University, Amsterdam, 16-19 July 1985.

(1) The military posture of NATO in general puts an increasing burden on military budgets, leads to increasing doubts concerning its military credibility. Furthermore, certan aspects of it decrease crisis-stability, make a return to a policy of détente increasingly difficult, are increasingly unacceptable to the general public.

(2) All participants rejected proposals based on striking moving targets deep inside WTO territory. A substantial group rejected strikes on all targets deep in Eastern Europe.

The organisers concluded that any proposals to procure $\mathrm{T}-16$ or T-22 missiles are unacceptable.

(3) Most participants supported a change of NATO policy in the direction of a more explicitly defensive military posture. This implies a greater ephasis on:

a heavily defended zone at the East-West border by use of small preplanned, prefabricated, rapidly deployable barriers and obstacles.

the use of light- and non-mechanised infantry, the use of reservists for this infantry.

a prepared communication system, dispersal and de-centralisation.

For differing reasons, it was argued that there should be less emphasis on explicitly offensive systems like the main battle tank.

(4) Non-provocative defence was defined as:

The build-up, training, logistics and doctrine of the armed forces are such that they are seen in their totality to be unsuitable for offence, but unambiguously sufficient for a credible defence. Nuclear weapons fulfil at most a retaliatory role. 